\title{
Impact of lean service, workplace environment, and social practices on the operational performance of India post service industry
}

\author{
Sengazhani Murugesan Vadivel ${ }^{1}$ - Aloysius Henry Sequeira ${ }^{2}$. \\ Robert Rajkumar Sakkariyas ${ }^{3} \cdot$ Kirubaharan Boobalan $^{4}$
}

Accepted: 20 April 2021 / Published online: 1 May 2021

(c) The Author(s), under exclusive licence to Springer Science+Business Media, LLC, part of Springer Nature 2021

\begin{abstract}
This paper aims to study the determinants of the Lean Service System (LSS) on the Operational Performance (OP) of India's mail service in the National Sorting Hub (NSH), Mangaluru, Karnataka, the southern part of India. Measuring the OP in mail service is a big challenge in the postal service industry. Hence, we have conducted a survey, and 150 usable data has measured the impact of Lean Service Practices (LSP), Lean Workplace Environment Practices (LWEP), and Lean Social Practices (LSoP) on the OP. The results are analyzed from the partial least square based structural equation modelling (PLSSEM) with the support of $\mathrm{R}$ programming. The analysis shows that there is positive and significant impact of $\operatorname{LSP}(\beta=0.380, p<.05)$, followed by LWEP $(\beta=0.281, p<.05)$, and LSoP $(\beta=0.266, p<.05)$ on OP. The practical effect of the findings of LSS are effectively implemented for enhancing the OP of the business. This research addresses the appropriate empirical model to test LSS in India's postal service industry, which is scant in the existing literature. Moreover, this study helps India Post to review its policy so as to sustain the effectiveness of Lean Service (LS) implementation.
\end{abstract}

Keywords Lean service practices (LSP) · Operational performance (OP) · Lean social practices (LSoP) · Lean workplace environment practices (LWEP) · PLS-SEM · Mail operations

$\begin{array}{ll}\text { Abbreviations } \\ \text { AM } & \text { Agile manufacturing } \\ \text { ANN } & \text { Artificial neural network } \\ \text { BWM } & \text { Best-worst method } \\ \text { DM } & \text { Decision makers } \\ \text { FGT } & \text { Focus group techniques } \\ \text { GDP } & \text { Gross domestic product } \\ \text { HFE } & \text { Human factors and ergonomics } \\ \text { I4T } & \text { Industry 4.0 technology }\end{array}$

Sengazhani Murugesan Vadivel ph.dvadivel@gmail.com

Extended author information available on the last page of the article 


$\begin{array}{ll}\text { ICHs } & \text { Intra circle hubs } \\ \text { JIT } & \text { Just in time } \\ \text { LM } & \text { Lean manufacturing } \\ \text { LMP } & \text { Lean manufacturing practices } \\ \text { LP } & \text { Lean practices } \\ \text { LPD } & \text { Lean product development } \\ \text { LPS } & \text { Lean production system } \\ \text { LS } & \text { Lean service } \\ \text { LSCM } & \text { Lean supply chain management } \\ \text { LSP } & \text { Lean service practices } \\ \text { LSS } & \text { Lean service system } \\ \text { LWEP } & \text { Lean workplace environment practices } \\ \text { MCDM } & \text { Multi-criteria decision making } \\ \text { MNOP } & \text { Mail network optimization project } \\ \text { NSH } & \text { National sorting hub } \\ \text { NVA } & \text { Non-value-added } \\ \text { OP } & \text { Operational performance } \\ \text { SC } & \text { Supply Chain } \\ \text { SEM } & \text { Structural equation modelling } \\ \text { SMEs } & \text { Small medium enterprises } \\ \text { SOP } & \text { Sustainable organisational performance } \\ \text { VSM } & \text { Value stream mapping } \\ \end{array}$

\section{Introduction}

Emerging technologies such as Industry 4.0 adopts cloud operations and artificial intelligence, and permits innovative and flexible production systems. Flexibility in manufacturing increases the ability of an organization to respond to consumer demands on time and increases the production system efficiency without sustaining unnecessary costs or utilization of excessive resources (Fragapane et al., 2020). Unpredictable or complex environments mostly exaggerate the manufacturing industries' operational performance and reliability. Thus, robustness is one of the most important metrics for assessing operational performance in the manufacturing industries (Chen et al., 2019).

In recent years, in both the academia and industrial sector, LM and Industry 4.0 are frequently used concepts for enhanced productivity and flexibility (Buer et al., 2018). Recently, Marodin et al. (2018) introduced lean implementation in the product development process, which is scant in the existing literature. Kamble et al. (2019) observed that LMP were a positive influence on SOP in Indian manufacturing companies. The present study also shows the significant direct and indirect effects of Industry 4.0 on SOP in the presence of LMP as a substantial mediating variable. Today, manufacturing industries are looking for LMP and environmental sustainability issues for competitive strategy. Bai et al. (2019) showed environmental and operational performance outcome while implementing lean system practices. LMP also discusses the triple bottom line approach such as economic, environmental, and social responsibility (Henao et al., 2019).

A study by Möldner et al. (2020) mentioned the process of innovation performance by incorporating LMP in manufacturing industries. The finding suggested that LMP has a medium effect on process innovation through the survey method. Abu et al. (2019) 
incorporated LMP in the furniture industry, which dealt with motivations, barriers, challenges, and applications. Ghobakhloo and Azar (2018) examined LM, Agile Manufacturing (AM), and impact on business performance. Interestingly, LM contributed to OP, while AM improved financial and marketing performance.

Globally, the service sector contributes to more than 50\% of the GDP of top economies (Anon, 2019). The service industry is exceptional compared with the manufacturing industry because of its heterogeneity, intangibility, simultaneity, inseparability, and perishability (Lovelock \& Gummesson, 2004). Service organizations usually look demand that differs the entire day such as mail processing facilities, airline service, healthcare, and customer care (Bard et al., 2003). For example, mail processing facilities require process improvement because of rapidly varying challenges brought about by fast hi-tech growth, alteration in consumers' requirements, and growing liberalization of the market. Thus, postal industries are required to improve their strategy to enhance production and cost-effectiveness to survive in a competitive market (Borenstein et al., 2004).

The India Post service is governed by the Central Government of India, and comes under the public sector. It is an essential public utility and plays a significant role in socioeconomic development. It utilizes all forms of transportation such as rail, road, air, and ship to transport its mail and parcels. Ineffective utilization of transportation can cause business interruptions and significant economic loss to a lean supply chain (Paul et al., 2019). It plays a vital role in providing social support through money transfer, payment of utility bills, mails, parcels, etc. Although such value-added services are available for the public, there is still a need to be fulfilled, as it should reach on time to the customers by increasing the delivery of articles in a day. It exploits the advantage of labour availability and has the widest network coverage in India.

In 2013, India Post introduced Hub \& Spoke mechanism for Speed Post articles under the MNOP. Eighty-nine main centres of the country were selected as Speed Post hubs and named as NSHs, and 105 major centres within the postal circles were selected and named as ICHs. The NSHs are responsible for dispatching inward mails to connected delivery post offices (spokes), and the same lines can send outward mails to within and outside the circle. India Post has 23 postal circles, generated from post offices and ICHs connected to it. NSH Mangalore won the first position among the 89 NSHs in the country during 2012-2014 in the handling of speed post. It covers postal divisions such as Puttur, Mangaluru, and Udupi regions and deals with 15,000 speed post articles in a day. The position was based on the points made by the India Post software (Source: Mangalore first in handling speed post, The Hindu Magazine, Indian Postal Service, Dec. 22, 2012). However, the performance decreased due to the administration's revised target set for NSH Mangalore (25,000-Speed Post articles a day) to increase the delivery of articles. Hence, in the present study, an attempt has been tried to increase the delivery of articles by assessing LSS performance in the postal service industry after lean incorporation. Many business organizations have incorporated LM strategies to respond rapidly to changing business conditions and to outdo the competition in recent years (Wu et al., 2016). The concern that has emerged in these businesses and organizations is the need to develop strategies to assess the performance of lean practices reliably.

\subsection{Significance of the study}

There are two main reasons why LS assessment is essential for the India Post service: 
1. India Posts in a million items losing significantly $12 \%$ of volume and market share from $2004 / 05$ to 2008/09. Also, customers have rated the India post having low reliability and earnings / In a million items, India Post has significantly lost $12 \%$ of volume and market share from 2004/05 to 2008/09. The customers have also rated India Post as having low reliability and earnings; and

2. The financial performance of India Post is low (-27\%) compared with other players like TNT, Singapore Post, and Deutsche Post concerning earnings before interest and tax report.

[as mentioned by MNOP conducted by McKensy (2010)].

\subsection{Statement of the problem}

1. Growing competition from the courier industry, rapid change in communication methods, customer loyalty, globalization, etc. are long-term challenges for the postal service to sustain in the market. Hence, a LS strategy and a non-traditional method will help to compete in the market.

2. The lengthy existing procedures/rules involved in the internal operations are time-consuming.

3. Standardization of operating procedure needs to be focused, because errors committed by the employees are on the high side (Ramachandran, 2011).

4. The working environment has cramped accommodation for its workers, with old and uncomfortable furniture, poor lighting, outdated tools, poor building infrastructure, shabby appearance, etc. Implementing LS through understanding the VSM current state and enhancing operational performance will improve the facility layout.

5. Customers of India Post are concerned about quality service with a high response in the shortest lead time. LS will improve productivity in the back-end operations by delivering mails to the addressee in the shortest lead time.

6. Improving physical working conditions such as lighting, ventilation facilities, ergonomic chairs, housekeeping, and quality culture in workplace will give an excellent public image, and improve OPs. LWEPs will help boost the postal system to a better working environment (Vadivel, 2015).

The present paper aims to examine LSS practices on OP in the NSH postal service by considering all the above factors. The paper is divided into seven main sections. Section 1 describes the introduction, significance of the study, problem statement. Section 2 deals with literature review and the formulation of research hypotheses. Section 3 presents the research methodology and the scale development of this process. Section 4 covers data analysis and the results. Section 5 deals with discussions, Sect. 6 covers the implications and conclusion of the study, and the final section sets forth the limitations and future recommendations for this research. 


\section{Literature review}

\subsection{Background study}

The globally renowned 'lean concept' was stated by Womack and Jones in the book, "Machines that Changed the World". LM focuses on finding and eliminating NVA activities (waste) in a product or service organization to create value for customers. The wastes are known as "TIMWOODS" (Transport, Inventory, Motion, Waiting, Over-processing, Overproduction, Defects and underutilization of resources). This waste is something that customers do not wish to pay, and is known as Non-Value-added Activities (NVA). Most well-known leading manufacturing companies have progressively implemented LM concepts. The benefit of LM is the same or more output with lesser inputs, i.e., material, machinery, workforce, space, and time. A typical LM conserve less than half of the inventory required at hand and lesser defects, while producing better variety of goods (Womack $\&$ Jones, 1990). The LM techniques facilitate more production volume in numerous industries, particularly in automobile industries and their vendors.

According to Lewis (2000), "Lean is a set of management philosophies for increasing production to reduce wastes" (NVA). LM requires multi-skilled employees, leadership, employees' coordination and commitment, etc. Toyota Production System (TPS) is the starting point of lean practices in manufacturing, which was slowly improved to identify and remove the wastes in the process flow inside the companies (Womack \& Jones, 1990).

Kiichiro Toyota, the founder of Toyota Motors, was immensely attracted by Henry Ford's mass production strategy. But, unfortunately, due to the economic situation in Japan after World War II, he was forced to adopt batch production instead of mass production of the vehicles (Dale et al., 2007). This situation helped Toyota build numerous model vehicles in a low volume by minimizing cost in shorter lead times. Thus, the LM concept helped produce high-quality cars at low prices of different models to satisfy customer needs (Dale et al., 2007). The LM goal of removing wastes in the process development contributed to product quality and created value to the customers.

\subsection{Empirical investigation on lean manufacturing practices}

Recent literature on LM empirically explored multifaced research areas such as sustainability with Industry 4.0, factory digitalization, product development cycle, process industries, human factors \& ergonomics, workplace environmental factors, supply chain frameworks, etc. Figure 1 shows both academicians' and practitioners' contributions to this empirical study.

Kamble et al. (2020) empirically investigated LMP on SOP with the integrated effect of I4T in Indian manufacturing industries. For that purpose, they have collected the data from 205 managers, currently working in different streams. The results showed that the direct and indirect impact of I4T on SOP was significant and confirmed the presence of LMP as a strong mediating variable. Sajan et al. (2017) investigated the LMPs in SMEs and the SOPs. They collected data from 252 Indian manufacturing SMEs. The findings indicated that LMPs are positively linked to different performances of sustainability such as economic, environmental, and social performance. Helleno et al. (2017) integrated sustainability principles in LM to asses in Brazilian manufacturing process industries through three case studies. They have included economic, social environmental factors in VSM. By incorporating environmental and OP results by implementing LMPs in six manufacturing 


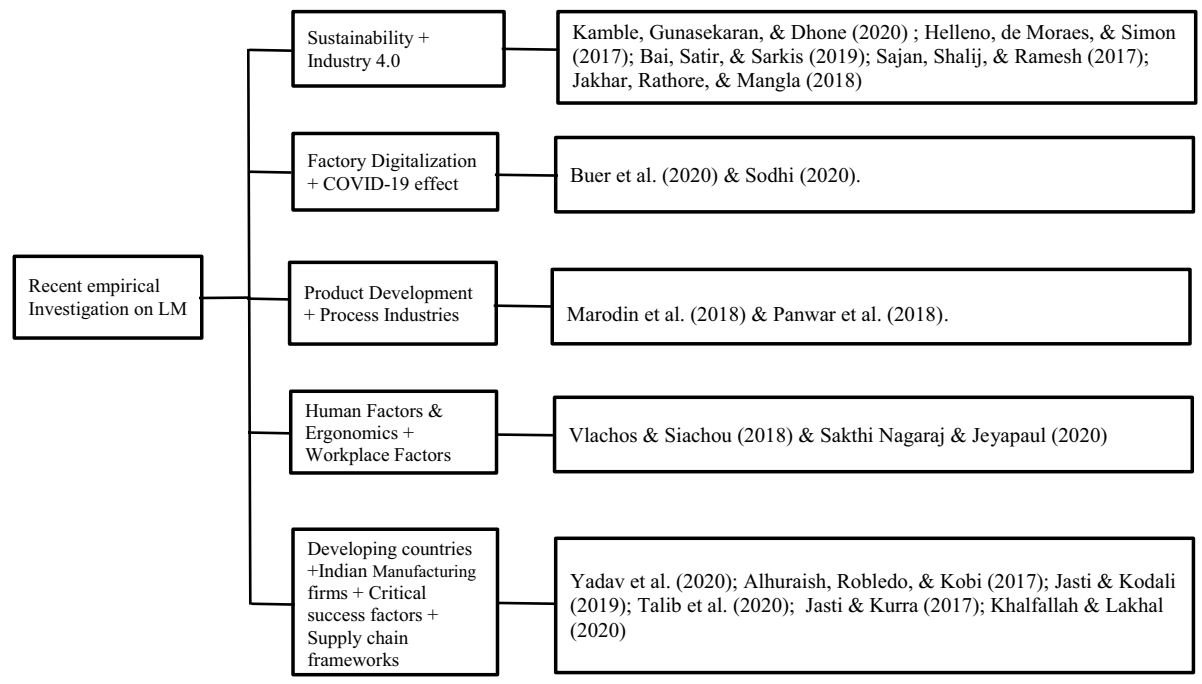

Fig. 1 Recent empirical study on lean manufacturing contributors

organisations, Bai et al. (2019) addressed the decision problem. A novel MCDM model was used to evaluate the environmental sustainability indicators through a better selection of LMPs, empirically tested data. Jakhar et al. (2018) examined the relationship between lean and green in the manufacturing industry with sustainable SC. Results obtained by the use of the SEM method show that lean implementation has a positive impact on the implementation of sustainability practices for supplier selection and production, but has a negative impact on sustainability practices for delivery and logistics services.

Based on data from a cross-sectional survey of manufacturing companies using hierarchical multiple regression analysis, Buer et al. (2020) explored the relations between LM, factory digitalization, and OP. The recovery of the Indian manufacturing sectors from coronavirus after-effects has been studied by Sodhi (2020), and he recommended lean six sigma tools and techniques.

Marodin et al. (2018) applied LM concepts in product development processes. They investigated empirically moderating the role of LPD on LM's impacts on quality and inventory performance. The results showed that the effect of LM on quality performance was a positive association and inventory turnover moderated by LPD practices. Panwar et al. (2018) adopted LMP in process industries. The results revealed that LMP has positively associated with OP and reduction in defects. However, in the process industries context, pull production found a marginal impact on OP.

Vlachos and Siachou (2018) empirically investigated workplace factors affecting LP in a global company. The findings revealed that LP is affected by workplace factors. Four LP variables, such as continuous improvement, waste, ergonomics, and product quality, are associated only with organisational culture. Sakthi Nagaraj and Jeyapaul (2020) examined the relationship between HFE and LM through survey data from 168 industry-lean experts. The study also documented that HFE was positively related to LP, and cognitive factors have the least influence.

The framework was developed by Yadav et al. (2020) to improve the adoption of LM processes in developing countries. Shop-floor management, quality management, and 
production strategy drivers were the most critical drivers for the LM system. Alhuraish et al. (2017) explored the comparative study on lean and six sigma critical success factors in industries. A road map was developed by Talib et al. (2020) to help DM to facilitate the successful implementation of the integrated JIT-LPs to improve the performance of the Indian manufacturing industries using BWM. Khalfallah and Lakhal (2020) empirically explored the link between LMPs, AM, and operational and financial performance in 205 Tunisian manufacturing firms. The results showed that, except for JIT production, LMP had a direct positive relationship with AM, (2) AM had a positive impact on OP, and (3) LMP did not seem to contribute directly to OP. However, when it was mediated through AM, this relationship is significant.

By questionnaire survey methodology, Jasti and Kurra (2017) empirically investigated the validity and reliability of current LSCM frameworks in the Indian manufacturing industry. It concluded that a new LSCM framework is needed to meet the requirements of the Indian manufacturing industry. Jasti and Kodali (2019) studied the LPS framework empirically on Indian manufacturing industries in various fields such as automotive, process, machinery and equipment, electronics and components, and textile and textile industries. Through the survey in that sector, they gathered 200 responses. This study concluded that the LPS framework helped any Indian manufacturing industry to achieve organizational goals.

\subsection{Lean system implemented in service industries}

Many works of literature have suggested that lean is implemented and assessed in different service sectors. For example, Alnajem et al. (2019), Hussain and Malik (2016), Agarwal et al. (2016), and Robinson et al. (2012) have implemented this study in different parts of a hospital such as emergency, cardiac catheterization laboratory, etc. Narayanamurthy et al. (2017) and Thomas et al. (2017) have implemented this in the higher educational institute sector to improve the course plan and to reduce absenteeism in class. Vlachos and Bogdanovic (2013) and Rauch et al. (2016) have implemented partial LS elements in a hotel to improve hospitality. Davidson (2014) and Procter and Radnor (2014) implemented lean in the public sector in the UK, to remove NVA and to improve the working system of public services. Table 1 shows a summary of the papers related to LS implemented in the service sectors.

\subsection{Hypotheses development}

\subsubsection{Lean service practices (LSP) impact on operational performance}

Firms are putting in efforts to improving service quality by incorporating Lean principles to increase profitability and customer goodwill. Lean in the service sector plays a significant role in increasing customers' value by offering services with higher quality and speeding-up the process by using lesser and right amount of resources (George \& George, 2003). Initially, some features of a LSS were endorsed by Bowen and Youngdahl (1998) from the LMS. Gradually, LS implementation increased in healthcare, education, public services, hotel, financial and IT industries, etc.

Most of the literature shows that the applicability of Lean practices in service industries presented promising results. But it did not show a comprehensive set of LSP in the service industries, particularly in mail service operations. Such sets are required for Lean 


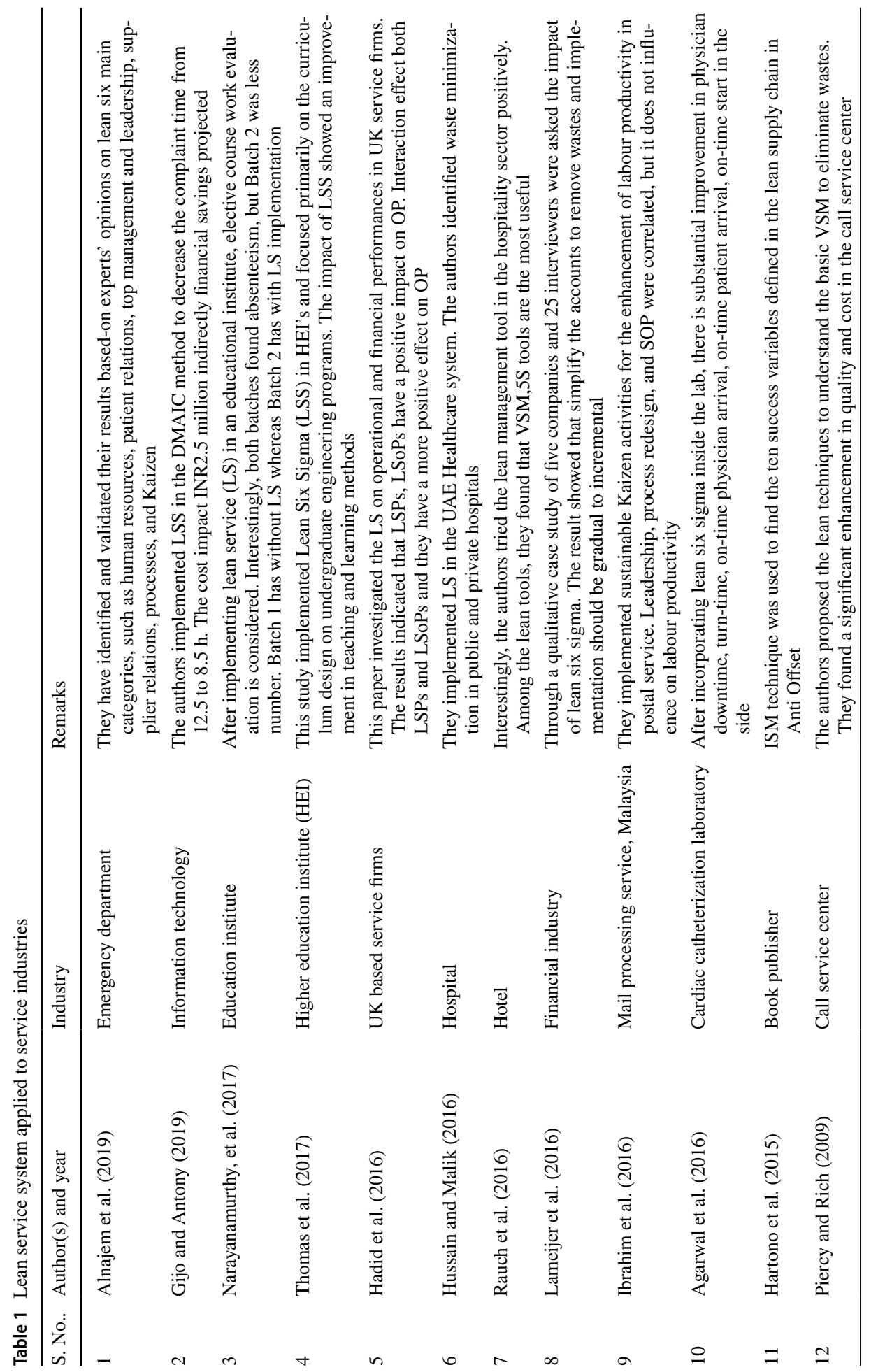




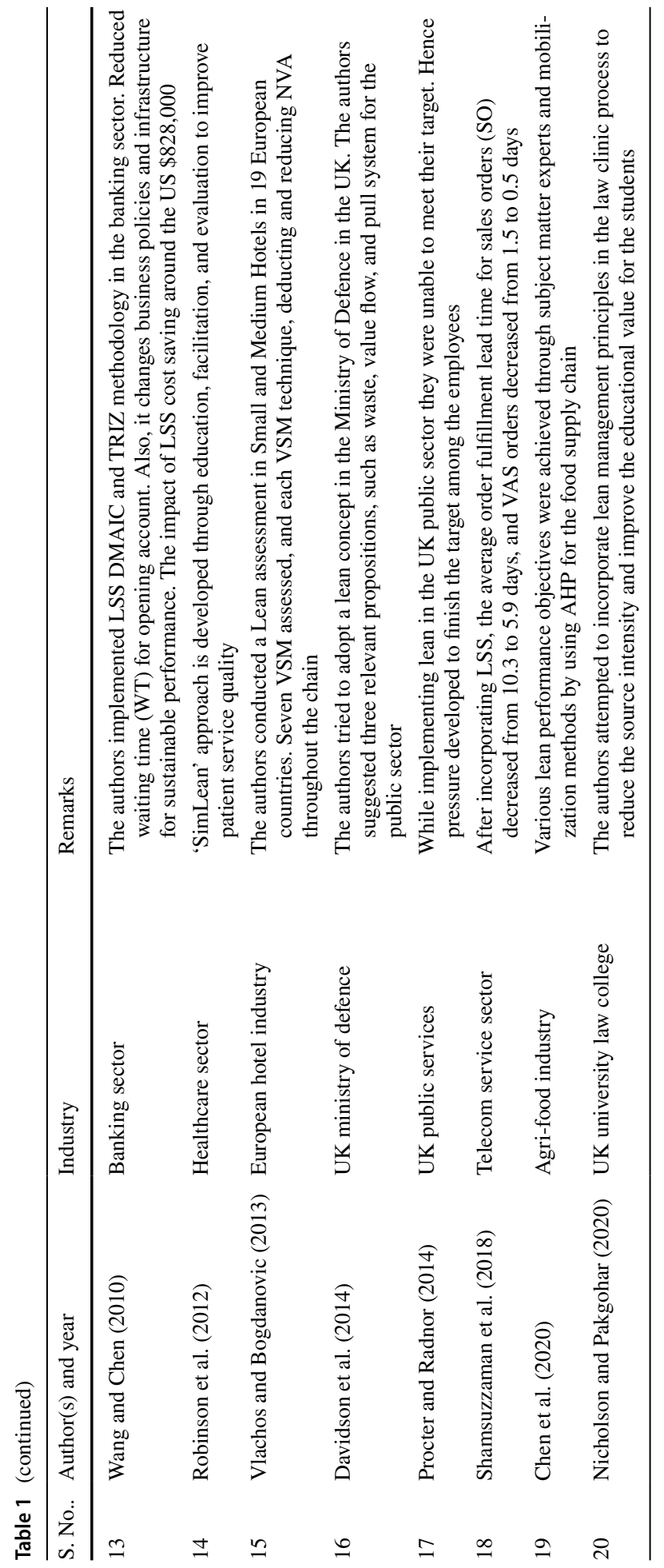


practitioners and scholars to know the impact of operational performance in the India Post service industry. The authors chose the most used service industries lean tools, and incorporated them in the mail service operations for improving operational performance and measured its impact.

Growing complications in the manufacturing or service environments and faster delivery of products or service with enhancing quality needs makes organizations often rethink their operations' strategy. Additionally, quality management practices play a role in improving OP for the firms' competitive advantage (Kaynak, 2003; Lagrosen \& Lagrosen, 2005). Shah and Ward (2003) made an association of LSP with OP. Further, the authors suggested that an operational performance should be analyzed by considering relatively multi-dimensional practices to each dimension. Some empirical studies evaluated the relationship between LSP and OP items (Callen et al., 2000; Fullerton \& McWatters, 2002; Ketokivi \& Schroeder, 2004). Conventionally, operational performance is characterized by operations' strategy for competitive priorities (Narasimhan \& Das, 2001).

According to Holweg (2007), LMP is an operational practice that creates value for the customers and eliminates waste with the spending resources. Khalfallah and Lakhal (2020) in an empirical study on Tunisian 205 manufacturing firms' LMP on operational performance showed that LMP contributed to operational performance through the mediation of agile manufacturing. The Lean assessment conducted by Ibrahim et al. (2020) on the Malaysian construction industry revealed a relationship between LMP and OP. LMP on Industry 4.0 adoption moderated the effect on operational performance according to the manufacturing firms. Particularly process-related technologies negatively moderated and product/service-related technologies positively moderated with OP (Tortorella et al. 2019).

In postal services, for improving the operational performance of the delivering mail articles, using the following strategies should be used:

- Optimize India Post's mail network from collection- to- delivery;

- Standardize processes with a focus on quality improvement and reduction in complexity; and

- Establish an effective performance management structure using key performance indicators (KPIs) and regular reviews.

Hence, the hypothesis is as follows:

Hypothesis H1a There is a positive and significant impact of Lean Service Practices (LSP) on Operational Performance (OP) in India Post service.

\subsubsection{Impact of lean workplace environment practices (LWEPs) on operational performance}

Globally, the workplace environment and its relationship to job satisfaction has been defined in different circumstances over the years. A Danish study proposed that an organization can grow its efficiency through improvement of the workplace environment (Buhai et al., 2008). Physical environmental conditions are essential while implementing Lean in an organization, especially for the manual sorting process. While incorporating Lean, employee involvement is a significant success factor that develops a healthy workplace environment (Ramachandran, 2011). Spector (1997) witnessed that most companies do not wish to pay attention to their workplace environment, affecting employee's performance. 
Bakotic and Babic (2013) identified that workplace environment is a significant issue for job satisfaction.

Chandrasekhar (2011) reasoned that firms need to pay more attention to workplace improvement to enhance internal productivity through the organization's profit. For example, lighting source is essential in a specific sorting section for reading and sorting the mails through postal pin codes. Research also reveals that poor lighting causes poor job performance such as dim, high glare, and poor light in the specific sorting section (Hemphälä, \& Eklund, 2012). Temperature also plays a vital role in the workplace environment as to how the human body attempts to keep an ideal temperature. Beshir et al. (1981) clarified that too much heat exposure significantly reduces the employee's performance within 30 min after exposure at $86^{\circ}$.

According to Ossama et al. (2006), indoor air quality is essential to a healthy, comfortable job for the employees. Some contaminants like dust and odours can form significant unpleasant feelings and discomfort leading to productivity loss as well as job performance. Presently, India Post is taking the necessary strategic actions to creating a better workplace environment such as postal appearance for more trustworthiness, reliable for customers, and improving the processing facilities for the betterment of postal employees. Murugesan et al. (2020) evaluated a postal facility layout design, as part of LSP in NSH Mangalore, wherein cost and workplace environment were the main criteria to enhance the articles delivery per day. Implementing $5 \mathrm{~S}$ and standardize activities led to attaining a more efficient, cleaner, and tidier workplace. In some companies' workplace, Lean implementation was less successful because of less used activities as mentioned by Dieste et al. (2020). Hence, the following hypothesis is formulated:

Hypothesis H2a There is a positive and significant impact of Lean Workplace Environment Practices (LWEP) on Operational Performance (OP) in the India Post services.

\subsubsection{Impact of lean social practices (LSoPs) on operational performance}

Lean social practices (LSoP) helps human resource features. Abdou et al. (2006) showed that LSoP had a positive effect on OP in the manufacturing sector. For example, a multiskill employee can handle simultaneous operations such as scanning and sorting during the bottleneck time. However, postal management has to give proper training, motivation, and employee empowerment to its employees. Therefore, management support is required for the employees for the rewarding system. In addition to this, Shah and Ward (2003), Cua et al. (2001), and Yasin et al. (2003) empirically tested LSoP and proved that it had positive impact on OP.

Interestingly, Tortorella et al. (2018) found a relationship between leadership style and LMP. While implementing LMP, different types of leadership styles are required. The study revealed that task orientation leaders were more interested in incorporating LMP than relation orientation leaders. A study conducted by Hernandez-Matias et al. (2019) in Spanish 202 manufacturing companies showed that Human-Related Lean Practices (HRLP) had a significant relationship with OP. By considering the above, the following hypothesis is formulated:

Hypothesis H3a There is a positive and significant impact of Lean Social Practices (LSoP) on Operational Performance (OP) in India Post service. 


\section{Research methodology}

\subsection{Scale development to measure OP in India post service}

The LSS dimensions and its items were generated from existing literature and Focus Group Techniques (FGT). The face validity of the scale was done by an expert panel of the Postmaster General, Postal Manager, Quality Manager, Academic Professors, and Research Scholars. Three independent variables (LSP, LWEP, and LSoP) and one dependent variable (Operational Performance) were identified. The study survey comprised of numerous multi-item constructs.

1. LSP: Lean tools and techniques applied to production enhancement such as VSM, Cellular layout, facility layout change, etc. Eleven items of LSP items as proposed by Hadid and Mansouri (2014) were considered.

2. LWEP: It refers to workplace environment such as ventilation and noise control. The construct LWEP was measured using nine items as proposed by Gopang et al. (2017) from Occupational Health and Safety Measures (OHSM).

3. LSoP: It refers to human/social relationship activities such as employee engagement, employee involvement, and performance measurement system. To measure LSoP, nine items as developed by Yasin et al. (2003) were considered.

4. Operational Performance (OP): It refers to non-financial performance measures/activities. The operation performance was measured using eleven items as endorsed by Hadid and Mansouri (2014).

Briefly, the LSS dimensions included LSP, LWEP, LSoP, and OP. Most of the items were fully considered from existing literature, and few items were modified according to the postal service requirements. Previous researchers or academicians did not pay much attention to LWEP items on OP, which is essential for manual working firms such as postal services. Figure 2 shows the flow chart of the scale validation of the work.

\subsection{Questionnaire design}

The questionnaire used in this study consists of the constructs; 1 . Lean Service Practices (LSPs), 2. Lean Workplace Environment Practices (LWEPs), 3. Lean Social Practices (LSoPs), and 4. Operational Performance (OP). Measures for these constructs have been adopted from earlier studies as mentioned. Items of these constructs have been measured using a 5-point Likert scale with weights strongly disagree as 1 to strongly agree as 5 and Neutral as 3 .

\subsection{Data collection approach}

After lean implementation, data were collected from 163 postal employees through a survey method. Then, the valid 150 responses were selected for analysis purposes. The sampling plan is shown in Fig. 3. 


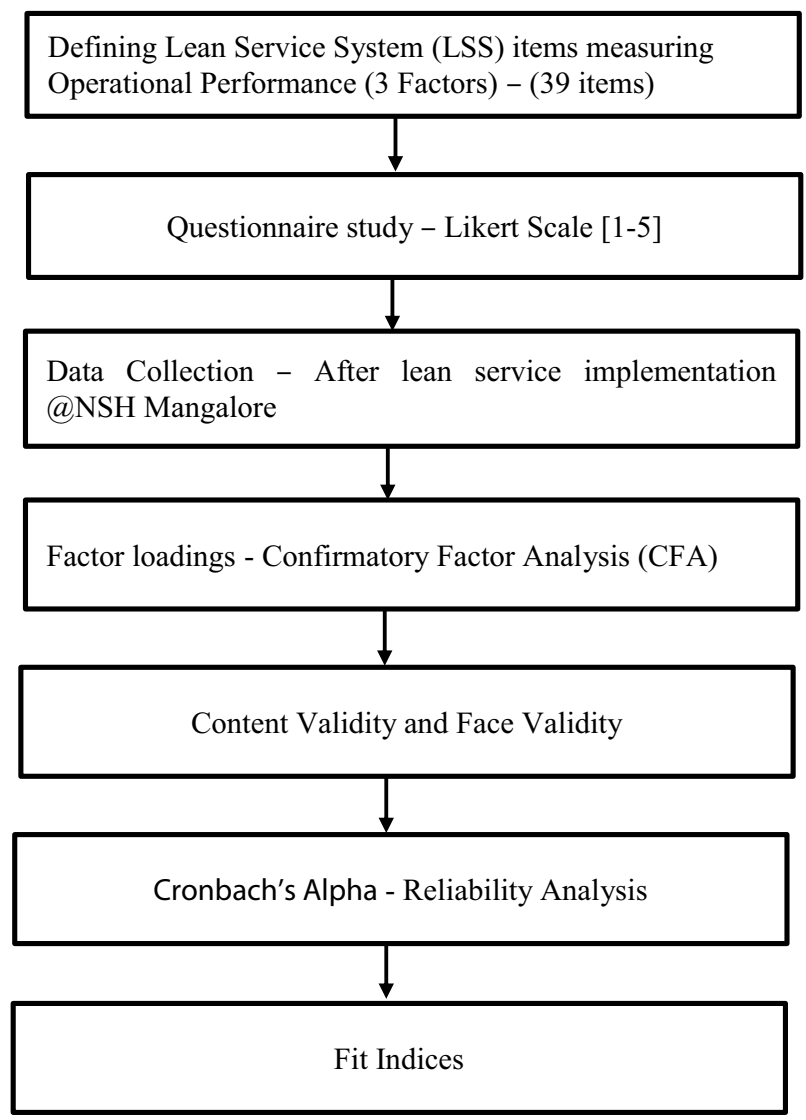

Fig. 2 Scale validation process

\section{Results and analysis}

\subsection{Statistical analysis}

The theoretical model was analyzed by the PLS-SEM procedure with the support of R programming (please refer to "Appendix"). Since the value of Mardia's coefficient is 173.59, which exceeds the cut-off value of 5, it indicates that the data is non-normal (Bentler, 2005), and the PLS-SEM technique fits well for the present study compared with the covariancebased SEM. Hair et al. (2011) and Ketchen (2013) had also suggested that the PLS-SEM can be used when the data points of the study were non-normal. Besides, the resampling method called bootstrapping with 5000 subsamples was used during model testing (Hair et al., 2011). The demographic details are given in Table 2. 


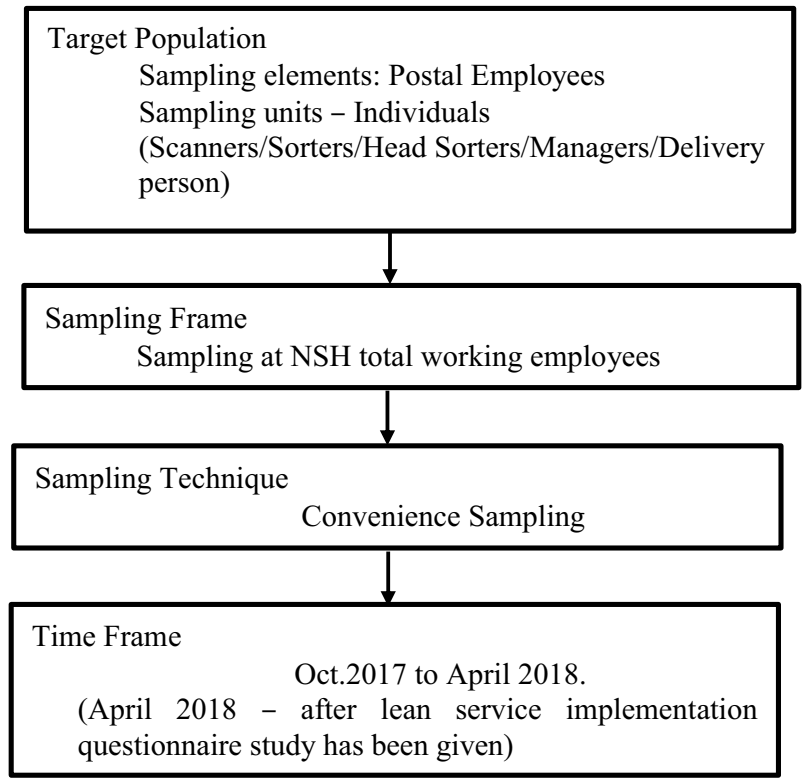

Fig. 3 Sampling process

Table 2 Demographics details for the study $(n=150)$

\begin{tabular}{lcc}
\hline Profile of respondents & \multicolumn{2}{c}{ Public postal service } \\
\cline { 2 - 3 } & Frequency $(\mathrm{n}=150)$ & Percent \\
\hline Gender & 30 & \\
Female & 120 & 20.0 \\
Male & & 80.0 \\
Age & 75 & \\
21-35 & 55 & 50.0 \\
36-50 & 20 & 36.7 \\
Above 51 & & 13.3 \\
Education level & 35 & \\
SSLC & 30 & 23.3 \\
Secondary education & 60 & 20.0 \\
Graduate & 25 & 40.0 \\
Post graduate & & 16.7 \\
Work experience & 45 & \\
Less than 3 years & 55 & 30.0 \\
4-14 & 20 & 36.7 \\
15-25 & 30 & 13.3 \\
More than 25 years & & 20.0 \\
Employment type & 85 & 56.7 \\
Permanent & 65 & 43.3 \\
Temporary & & \\
\hline
\end{tabular}




\subsection{Harman's single factor test of common method bias}

\subsubsection{Common method bias}

The common method bias problem can be ruled out by conducting Harman's single factor test. For this, the exploratory factor analysis was conducted without the factor rotation. In the present study, the first factor extracted $34.46 \%$ of the variance, which was less than $50 \%$, indicating the absence of a common method bias issue as suggested by Hair et al. (1998). Besides, the Variance Inflation Factor (VIF) value of each variable exceeded the cut-off value of 3 , which again confirmed the absence of a common method bias problem (Kock, 2017).

\subsection{Measurement model results}

The measurement model results are shown in Table 3. Composite reliability (CR), convergent validity (AVE), item loadings, and variance inflation factor (VIF) are presented in Table 3. Similarly, Heterotrait-Monotrait Ratio (HTMT) used to assess the discriminant validity of the used constructs also presented in Table 3.

The standardized loadings of items in their matching constructs were significant at a 5\% confidence level. But some items in LSP (i.e., 6,8,10, and11), LWEP (i.e., 5, 6, and 9), LSOP (i.e., 2 and 4), and OP (i.e. 1, 5, and 6) had insignificant loadings on their corresponding constructs, and thus were detached from further analysis. However, the composite reliability (CR) of the study constructs surpassed the value of 0.7 . It indicated the presence of internal consistency of the latent variables used in the study (Hair et al., 2011). Further, the existence of convergent validity was confirmed by the AVE value, which also exceeded the cut-off value of 0.5 indicating a good fit (Fornell \& Larcker, 1981). Besides, the multi-collinearity problem was examined by observing the VIF values (Variance Inflation Factor), and all the constructs had a VIF value of less than 5, indicating that the study constructs were free from the multi-collinearity issue (Rogerson, 2001).

As suggested by Henseler et al. (2014), the existence of discriminant validity was estimated by the "Heterotrait-Monotrait Ratio" (HTMT), which is shown in Table 4, wherein the diagonal values represent the HTMT values of each construct. In addition, the values were below the cut-off value of 0.85 , indicating the presence of discriminant validity. Overall, the present study presented adequate evidence for the presence of convergent and discriminant validity.

\subsection{Testing the structural model}

The standardized coefficient of each hypothesized relationship, along with its corresponding significance level, is shown in Table 5.

The results of the structural model analysis indicate that all the direct hypotheses (i.e., $\mathrm{H}_{1}, \mathrm{H}_{2}$, and $\mathrm{H}_{3}$ ) are positive and statistically significant, and in line with the expected assumptions. The relationship concerning LSPs $\rightarrow$ OP was found to be positive and significant (i.e., $\beta=0.330, p<.05$ ) for the samples. Moreover, the hypothesized relationships LWEPs $\rightarrow$ OP $(\beta=0.281, p<.05)$ and LSoPs $\rightarrow$ OP $(\beta=0.266, p<.05)$ were also found to 
Table 3 Measurement model results (item loadings, VIF, AVE and CR values)

\begin{tabular}{|c|c|c|c|c|}
\hline Constructs & $\lambda(>0.5)$ & $\alpha(>0.7)$ & $\operatorname{AVE}(>0.5)$ & $\operatorname{VIF}(<5)$ \\
\hline \multicolumn{5}{|l|}{$L S P$} \\
\hline Value Stream Mapping & $0.738 * *$ & 0.845 & 0.562 & 2.793 \\
\hline Improving facility layout & $0.720 * *$ & & & \\
\hline Cellular layout & $0.719 * *$ & & & \\
\hline Single piece flow & $0.716^{* *}$ & & & \\
\hline Workload balancing & $0.591 * *$ & & & \\
\hline Reduce cycle time & $0.728 * *$ & & & \\
\hline $5 \mathrm{~S}$ & $0.595 * *$ & & & \\
\hline \multicolumn{5}{|l|}{$L W E P$} \\
\hline Lighting facilities & $0.699 * *$ & 0.849 & 0.624 & 3.077 \\
\hline Ventilation facilities & $0.690 * *$ & & & \\
\hline Visual Identification & $0.759 * *$ & & & \\
\hline Workspace & $0.713 * *$ & & & \\
\hline Drinking water facilities & $0.660 * *$ & & & \\
\hline Noise Control & $0.646 * *$ & & & \\
\hline \multicolumn{5}{|l|}{ LSoP } \\
\hline Employee communication system & $0.640 * *$ & 0.867 & 0.597 & 2.498 \\
\hline Employee commitment & $0.546^{* *}$ & & & \\
\hline Leadership & $0.792 * *$ & & & \\
\hline Employee involvement & $0.749 * *$ & & & \\
\hline Multi skill task & $0.727 * *$ & & & \\
\hline Management support & $0.726^{* *}$ & & & \\
\hline Training & $0.660 * *$ & & & \\
\hline \multicolumn{5}{|l|}{$O P$} \\
\hline Improvement in production & $0.512 * *$ & 0.825 & 0.538 & 2.606 \\
\hline Improvement in employee performance & $0.558 * *$ & & & \\
\hline Employee understanding the process & $0.744 * *$ & & & \\
\hline Improvement in housekeeping & $0.728 * *$ & & & \\
\hline Reduction in Inventory & $0.771 * *$ & & & \\
\hline Reduction in cycle time & $0.658 * *$ & & & \\
\hline Reduction in human errors & $0.632 * *$ & & & \\
\hline
\end{tabular}

$* * p<.05, \lambda$ loading, $\alpha$ composite reliability, $A V E$ average variance extracted, VIF variance inflation factor

Table 4 Discriminant validity (heterotrait-monotrait ratio)

\begin{tabular}{lrrrr}
\hline Constructs & 1 & \multicolumn{1}{l}{ 2 } & \multicolumn{1}{l}{3} & \multicolumn{1}{l}{4} \\
\hline 1. LSP & 1 & .677 & .680 & .585 \\
2. LWEP & & 1 & .648 & .773 \\
3. LSOP & & & 1 & .668 \\
4. OP & & & & 1 \\
\hline
\end{tabular}


Table 5 Structural model results

\begin{tabular}{llll}
\hline Structural paths & \multicolumn{2}{l}{ Direct effects (standardized coefficients) } \\
\cline { 2 - 4 } & Estimate $(\beta)$ & $\begin{array}{l}\text { Percentile method (i.e. 95\% } \\
\text { significance level) }\end{array}$ \\
\cline { 3 - 4 } & & $\begin{array}{l}\text { Lower bound } \\
(0.025)\end{array}$ & $\begin{array}{l}\text { Lower } \\
\text { bound } \\
(0.975)\end{array}$ \\
\hline $\mathrm{LSP} \rightarrow$ OP & $0.330^{* *}$ & 0.127 & 0.421 \\
$\mathrm{LSOP} \rightarrow$ OP & $0.266 * *$ & 0.066 & 0.562 \\
$\mathrm{LWEP} \rightarrow$ OP & $0.281 * *$ & 0.140 & 0.437 \\
\hline
\end{tabular}

LSP lean service practice, $L W E P$ lean workplace environment practice, $L S O P$ lean social practice, $O P$ operation performance, $* * \rightarrow p<.05$

Table 6 R square, $\mathrm{Q}$ square values, and GOF values

\begin{tabular}{lccc}
\hline Dependent factors & $\mathrm{R}^{2}$ & $\mathrm{Q}^{2}$ & $\mathrm{GOF}$ \\
\hline Operation Performance & 0.627 & 0.246 & 0.535 \\
\hline $\begin{array}{l}\mathrm{R}^{2}=\text { Coefficient } \text { of determination, } \\
\text { goodness of fit }\end{array}$ & $\mathrm{Q}^{2}=$ Predictive & relevance, & GOF
\end{tabular}

be positive and significant. The values of the goodness of fit (GoF), R square $\left(R^{2}\right)$, and $Q$ square $\left(\mathrm{Q}^{2}\right)$ of the model are shown in Table 6 .

In the present study, the model has only one endogenous variable (i.e., operational performance), and the explained variance $\left(\mathrm{R}^{2}\right)$ on it was $62.7 \%$. Moreover, the predictive relevance of the model was estimated by the measure $\mathrm{Q}^{2}$, and the value of $\mathrm{Q}^{2}$ should be greater than zero as suggested by Hair et al. (2014). In this study, the value of $\mathrm{Q}^{2}$ was 0.24 for operational performance. Thus, the model has good predictive relevance since the value of $\mathrm{Q}^{2}$ exceeded zero. Moreover, the goodness of fit (i.e., evaluating the predicting global supremacy of the model) of the model was determined by using the formula:

$$
\text { Gof }=\sqrt{\overline{A V E}} * \sqrt{\overline{R^{2}}}
$$

Tenenhaus et al. (2005) suggested that if the GoF value of the model exceeded the limit of 0.36 , then it was said to have good predictive power. In the present study, the model's GoF was 0.53 , which designates that the present study model has good predictive power.

\section{Discussions}

In the present study, LSS practices (i.e., LSP, LWEP, and LSoP) have a significant and positive impact on OP in the India Post service. However, Lean Social Practices have low significant impact $(\beta=0.266, p<.05)$ on OP compared with LSP and LWEP.

From Fig. 4, LSP was found to be statistically significant on OP. The result is in agreement with the findings of Hadid et al. (2016) and Arumugam et al. (2020) (see Table 7). With the top management of the postal service recognizing the significance of LS tools 


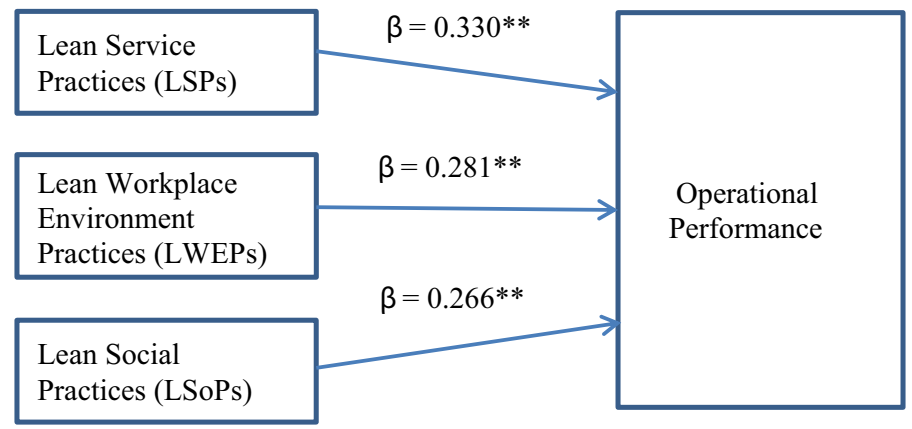

Fig. 4 A path model of LSS and operational performance

and techniques, operational performance can be improved. The results of the present study reveal that manager and employee commitment for LSP can help the postal service improve production without disturbing the daily routine activities. Applicable LS elements were incorporated in the NSH and manual sorting centre, and waste was eliminated by taking suitable course of action. Here, the cellular approach (Nagare cell) was used to reduce the walking distance in the sorting section. Reduction in cycle time and employee shoulder pain was taken care of by installing a fixed scanner; $5 \mathrm{~S}$ for housekeeping concepts for everything; everything in its place. Visual management for visualizing the objects in the workplace. Single piece flow was adopted for reducing backtracking of mails. Workload balancing was availed for maintaining load uniformity to all employees by using systematic scheduling and careful analysis. The impact of the change and adherence to the recommendations were monitored continuously. After twelve weeks, an audit of the effect was performed, and the following was observed. The cycle time had reduced by $15.13 \%$ from $371 \mathrm{~s}$; flow speed had increased by $11.36 \%$ from 590, individual article processed per person had increased by $11.36 \%$ from 8620 .

From Hypothesis H2, LWEP was a significant factor with OP. Earlier works of Ajala (2012) and Gopang et al. (2017) recommended that a postal workplace environmental performance can be enhanced by suitable Occupational Health and Safety Measures (OHSM), and showed LWEP modifications of light arrangements, provision of ventilation facilities, whitewashing the wall, improving visual identification by implementing $5 \mathrm{~S}$, posters, inspiring cleanliness quotes, providing drinking water facility, and provision of equipment. For enhancing the sorting process through ease of readability such as local mails, pin code tags visible by a blue background with white text were issued. For non-local mails, pin code tags were red background with white text. Focusing light was provided on the top of the sorting box to improve visual ergonomics. The workplace was made to look neat by separating the scanning, sorting, sealing, and parcel section with suitable tape marking provision. Now, the workplace environment looked pretty and aesthetic. In the scanning section, a moving scanner was used earlier for scanning the articles. From the interview, it was understood that the bulk of articles in a day made the employees uncomfortable, causing pain in the shoulder, elbow joints, and wrists. Hence, a new method of fixed scanning method was proposed, which reduced the cycle time by $23.62 \%$, and reduced Muskelotical Disorder (MSD) problems for the future.

LSoP was also found to have a substantial effect on OP. This was bolstered by previous outcomes from Arumugam et al. (2020). After implementing Lean, activities such as employee 


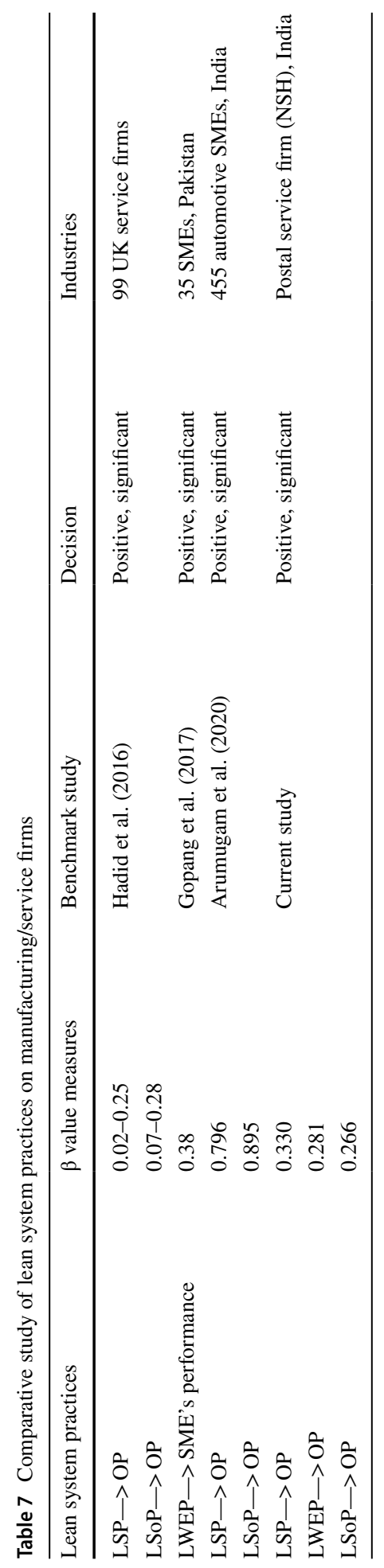


involvement, engagement, and management support was more. Employee commitment to understanding the role of lean implementation was better. Lean incorporation improved multitasking, employee empowerment, and communication system. However, it was an incremental stage. The results showed that LSoP had a beta value (0.035), which was less compared with the value of Arumugam et al. (2020) as mentioned in Table 7. Specifically, the present study also concluded that LSoP needed more attention in terms of social practices among postal employees, i.e., communication improvement, employee involvement, and training requirement, and consistent performance measurement. The postal administration has to pay much attention to these significant and viable methods to improve social practices. It is therefore, recommended that postal authorities and policymakers should make efforts to implement LSoP effectively. NSH has to perform these crucial parameters to compete locally and globally and implement complete LSS practices for the sustainable development of the country's economic position.

\section{Implications of the study}

The practical purpose of the present study was to provide enterprises wishing to develop their operations with a clearer understanding of specific LSS procedures that can be implemented in their service firms. The management team can also use the study results as a self-diagnostic method to evaluate and recognize areas in their current LSS practices in relation to OP, and the clear changes required. The result revealed that LSS practices in the form of LSP, LWEP, and LSoP are positively significant with OP. LSP has the most reliable beta coefficient from the sample done in the postal service, followed by LWEP, and LSoP. This implies that for any technical breakthrough or progress to be made, top management dedication and support for LSS is crucial. Leadership oriented strategy in the workplace and social practices are vital for a sharp corporate postal image.

The present empirical study examines the association within the postal service between the three LSS practices and OP. The research offers some initial proof that these activities can help businesses achieve competitive advantage through a higher degree of creative capability. The research confirms, given the theoretical and empirical support, that LSS practices can be fully conceptualized as governing the occurrence and effectiveness of OP in postal service firms. By studying the various dimensions of LSS, both researchers and practitioners can understand how the different items of LSS can contribute to OP. In enterprises view, LSS activities as a beneficial part of their corporate strategy and offer full support to the initiatives, it can positively affect future successes. The strength of the impact of LSS practices on OP is based purely on how well the postal sector implements or continuously sustains the process. Finally, the Indian postal department agrees that LSS is a technological, social, and workplace environmental improved method that requires additional policies and procedures for sustainable development. In fact, in April 2018, NSH postal service spent INR 2 lakhs for this lean implementation and assessment. Thus, the practical implications of this study could be justified. 


\section{Conclusions}

The present study aims to examine the significant positive impact of LSS practices on OP in India Post services. To respond, with these three hypotheses $\left(\mathrm{H}_{1}, \mathrm{H}_{2}, \mathrm{H}_{3}\right)$, The findings showed that LSP, LWEP, and LSoP have significant and positive impact on OP. LSP $(\beta=0.330, p=<.05)$ was the main element that strongly impacted on OP, followed by LWEP $(\beta=0.281, p=<.05)$ and LSoP $(\beta=0.266, p=<.05)$. The current research takes into account consequences for two viewpoints, for example, theoretical and managerial. From a theoretical perspective, the present work establishes and analyzes a conceptual model that suggests relationships between the postal firm's LSS practices and the OP introduced. Previous studies on LSS have observed the technical and social performance of lean implementation, but little attention has been given to workplace environmental practices. Furthermore, past operations' management literature focused the lean has technical and social practices, but very less on workplace environmental practices, and the present study has achieved that purpose for manual labor in the postal service.

\subsection{Limitations of the research and future recommendations}

Few limitations of the present research are highlighted as follows: Firstly, the study adopted the questionnaire method. It recommended that detailed field survey and interview methods might overcome the response bias. Secondly, the sample size was less. Thirdly, the study was analyzed using advanced SEM-ANN analysis to predict and enhance the results' reliability and validity. However, the present study was carried out in India Post and was limited as a case study. Hence, the outcomes of the present research represent a specific region only. LSS implementation in the postal service sector in an original methodology ensures maximum economic benefit for the postal administration. In the future, LSS can be analyzed to measure financial and organizational performances. This analysis can be further explored to the rest of the lean sets, which may depend on specific industries and countries. 


\section{Appendix}

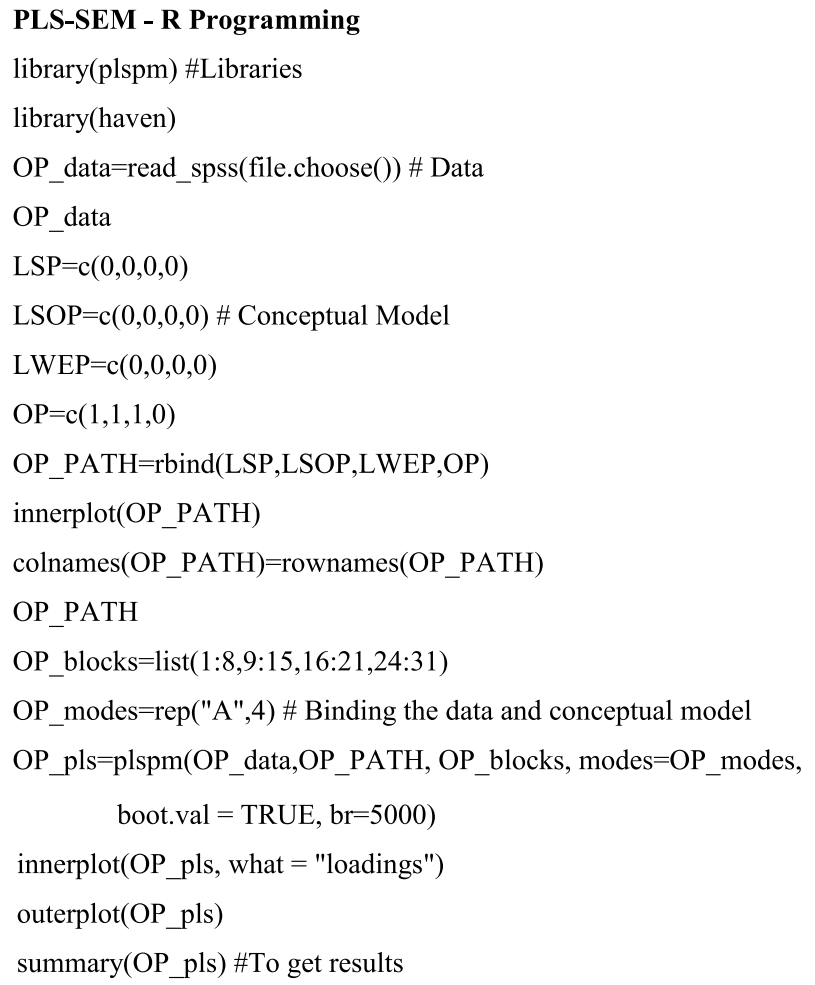

\section{References}

Abdou, A., Ossama, G. M., Kholy., \& Amal Abdou A .(2006). Correlation between indoor environmental quality and productivity in building. In: The 19th IAPS Conference, vol. 732, (pp.1-15). Alexandria, Egypt.

Abu, F., Gholami, H., Saman, M. Z. M., Zakuan, N., \& Streimikiene, D. (2019). The implementation of lean manufacturing in the furniture industry: A review and analysis on the motives, barriers, challenges, and applications. Journal of Cleaner Production, 234, 660-680

Agarwal, S., Gallo, J. J., Parashar, A., Agarwal, K. K., Ellis, S. G., Khot, U. N., Spooner, R., Tuzcu, E. M., \& Kapadia, S. R. (2016). Impact of lean six sigma process improvement methodology on cardiac catheterization laboratory efficiency. Cardiovascular Revascularization Medicine, 17(2), 95-101

Ajala, E. M. (2012). The influence of the workplace environment on workers' welfare, performance, and productivity. In: The African Symposium.Vol. 12 (pp. 141-149).

Alhuraish, I., Robledo, C., \& Kobi, A. (2017). A comparative exploration of lean manufacturing and six sigma in terms of their critical success factors. Journal of Cleaner Production, 164, 325-337

Alnajem, M., Garza-Reyes, J. A., \& Antony, J. (2019). Lean readiness within emergency departments: a conceptual framework. Benchmarking: An International Journal, 26(6), 1874-1904

Anon. (2019). Services sector. Retrieved July, 2019, from http://indiabudget.nic/echap-10.pdf 
Arumugam, V., Kannabiran, G., \& Vinodh, S. (2020). Impact of technical and social lean practices on SMEs' performance in the automobile industry: A structural equation modeling (SEM) analysis. Total Quality Management \& Business Excellence. https://doi.org/10.1080/14783363.2020.17910 67

Bai, C., Satir, A., \& Sarkis, J. (2019). Investing in lean manufacturing practices: An environmental and operational perspective. International Journal of Production Research, 57(4), 1037-1051

Bakotic, D., \& Babic, T. (2013). Relationship between working conditions and job satisfaction: The case of Croatian shipbuilding company. International Journal of Business and Social Science, 4(2), 1-8

Bard, J. F., Binici, C., \& Desilva, A. H. (2003). Staff scheduling at the United States postal service. Computers and Operations Research, 30(5), 745-771

Bentler, P. M. (2005). EQS 6 structural equations program manual. Retrieved 10 October 2009.

Borenstein, D., Luiz-Becker, J., \& José-do-Prado, V. (2004). Measuring the efficiency of Brazilian post office stores using data envelopment analysis. International Journal of Operations and Production Management, 24(10), 1055-1078

Bowen, D. E., \& Youngdahl, W. E. (1998). Lean service: In defense of a production-line approach. International Journal of Service Industry Management, 9(3), 207-225

Buer, S. V., Strandhagen, J. O., \& Chan, F. T. (2018). The link between Industry 4.0 and lean manufacturing: Mapping current research and establishing a research agenda. International Journal of Production Research, 56(8), 2924-2940

Buer, S. V., Semini, M., Strandhagen, J. O., \& Sgarbossa, F. (2020). The complementary effect of lean manufacturing and digitalisation on operational performance. International Journal of Production Research, 59, 1-17

Buhai, S. I., Cottini, E., Westergaard-Nielsen, N. (2008). The impact of workplace conditions on firm performance. Tinbergen Institute Discussion Paper No. 08-077/3, Available at SSRN: https://ssrn. com/abstract $=1262698$ or https://doi.org/10.2139/ssrn.1262698

Callen, J. L., Fader, C., \& Krinsky, I. (2000). Just-in-time: A cross-sectional plant analysis. International Journal of Production Economics, 63(3), 277-301

Chandrasekar, K. (2011). Workplace environment and its impact organizational performance in public sector organizations. International Journal of Enterprise Computing and Business Systems, 1(1), $1-19$

Chen, H., Liu, S., \& Oderanti, F. (2020). A knowledge network and mobilisation framework for lean supply chain decisions in agri-food industry. Supply chain and logistics management: Concepts, methodologies, tools, and applications. (pp. 369-381). IGI Global.

Chen, Y., Zhou, H., Huang, P., Chou, F., \& Huang, S. (2019). A refined order release method for achieving robustness of non-repetitive dynamic manufacturing system performance. Annals of Operations Research. https://doi.org/10.1007/s10479-019-03484-9

Cua, K. O., McKone, K. E., \& Schroeder, R. G. (2001). Relationships between implementation of TQM, JIT and TPM and manufacturing performance. Journal of Operations Management, 19, 675-694

Dale, B. G., Van Der Wiele, T., \& Van Iwaarden, J. (2007). Managing quality. Wiley.

Davidson, N. B. P. H. P. (2014). Wider applications for lean: An examination of the fundamental principles within public sector organisations. International Journal of Productivity and Performance Management, 63(5), 550-568

Dieste, M., Panizzolo, R., \& Garza-Reyes, J. A. (2020). Evaluating the impact of lean practices on environmental performance: Evidence from five manufacturing companies. Production Planning and Control, 31(9), 739-756

Fornell, C., \& Larcker, D. F. (1981). Evaluating structural equation models with unobservable variables and measurement error. Journal of Marketing Research, 18(1), 39. https://doi.org/10.2307/3151312

Fragapane, G., Ivanov, D., Peron, M., Sgarbossa, F., \& Strandhagen, J. O. (2020). Increasing flexibility and productivity in industry 4.0 production networks with autonomous mobile robots and smart intralogistics. Annals of operations research, 1-19.

Fullerton, R. R., \& McWatters, C. S. (2002). The role of performance measures and incentive systems in relation to the degree of JIT implementation. Accounting, Organizations and Society, 27(8), 711-735

George, M. L., \& George, M. (2003). Lean six sigma for service. McGraw-Hill.

Ghobakhloo, M., \& Azar, A. (2018). Business excellence via advanced manufacturing technology and lean-agile manufacturing. Journal of Manufacturing Technology Management, 29(1), 2-24

Gijo, E. V., \& Antony, J. (2019). Application of lean six sigma in IT support services-a case study. The TQM Journal, 31(3), 417-435

Gopalakrishnan, N., \& Gurumurthy, A. R. C. (2017). Applying lean thinking in an educational instituteAn action reseach. International Journal of Productivity and Performance Management, 66(5), 598629. https://doi.org/10.1108/IJPPM-07-2016-0144 
Gopang, M. A., Nebhwani, M., Khatri, A., \& Marri, H. B. (2017). An assessment of occupational health and safety measures and performance of SMEs: An empirical investigation. Safety Science, 93, 127-133

Hadid, W., \& Mansouri, S. A. (2014). The lean-performance relationship in services: A theoretical model. International Journal of Operations and Production Management., 34(6), 750-785

Hadid, W., Mansouri, S. A., \& Gallear, D. (2016). Is lean service promising? A socio-technical perspective. International Journal of Operations and Production Management, 36(6), 618-642

Hair, J. F., Black, W. C., Babin, B. J., Anderson, R. E., \& Tatham, R. L. (1998). Multivariate data analysis (207-219). Prentice-Hall.

Hair, J. F., Hult, G. T. M., Ringle, C., \& Sarstedt, M. (2014). A primer on partial least squares structural equation modeling (PLS-SEM)(1st ed.,). Sage publications. Retrieved from https://books.google.co. in/books?hl=en\&lr=\&id=Xn-LCwAAQBAJ\&oi=fnd\&pg=PA9\&dq=A+primer+on +partial+least+ squares+structural+equation+modeling \&ots=sm65rUeORC\&sig=pY8DkzLq5Kg2kcfqCdmxPdLzf $\mathrm{u} 0 \# \mathrm{v}=$ onepage $\& \mathrm{q}=\mathrm{A}$ primer on partial least squares structural equation $\bmod$

Hair, J. F., Ringle, C. M., \& Sarstedt, M. (2011). PLS-SEM: Indeed a silver bullet. Journal of Marketing Theory and Practice, 19(2), 139-152. https://doi.org/10.2753/mtp1069-6679190202

Helleno, A. L., de Moraes, A. J. I., \& Simon, A. T. (2017). Integrating sustainability indicators and lean manufacturing to assess manufacturing processes: Application case studies in Brazilian industry. Journal of Cleaner Production, 153, 405-416

Hemphälä, H., \& Eklund, J. (2012). A visual ergonomics intervention in mail sorting facilities: Effects on eyes, muscles, and productivity. Applied Ergonomics, 43(1), 217-229

Henseler, J., Ringle, C. M., \& Sarstedt, M. (2014). A new criterion for assessing discriminant validity in variance-based structural equation modeling. Journal of the Academy of Marketing Science, 43(1), 115-135. https://doi.org/10.1007/s11747-014-0403-8

Henao, R., Sarache, W., \& Gómez, I. (2019). Lean manufacturing and sustainable performance: Trends and future challenges. Journal of cleaner production, 208, 99-116

Hernandez-Matias, J. C., Ocampo, J. R., Hidalgo, A., \& Vizan, A. (2019). Lean manufacturing and operational performance. Journal of Manufacturing Technology Management., 31(2), 217-235

Hartono, Y., Diar, R., \& Jin, T. (2015). Enabler to successful implementation of lean supply chain in a book publisher. Procedia Manufacturing, 4, 192-199. https://doi.org/10.1016/j.promfg.2015.11.031

Holweg, M. (2007). The genealogy of lean production. Journal of Operations Management, 25, 420-437

Hussain, M., \& Malik, M. (2016). Prioritizing lean management practices in public and private hospitals. Journal of Health Organization and Management, 30(3), 457-474

Ibrahim, A. R., Imtiaz, G., Mujtaba, B., Vinh Vo, X., \& Ahmed, Z. U. (2020). Operational excellence through lean manufacturing: Considerations for productivity management in Malaysia's construction industry. Journal of Transnational Management, 25(3), 225-256. https://doi.org/10.1080/15475778. 2020.1749809

Jakhar, S. K., Rathore, H., \& Mangla, S. K. (2018). Is lean synergistic with sustainable supply chain? An empirical investigation from emerging economy. Resources, Conservation and Recycling, 139, 262-269

Jasti, N. V. K., \& Kodali, R. (2019). An empirical investigation on lean production system framework in the Indian manufacturing industry. Benchmarking: An International Journal, 26(1), 296-316

Jasti, N. V. K., \& Kurra, S. (2017). An empirical investigation on lean supply chain management frameworks in Indian manufacturing industry. International Journal of Productivity and Performance Management., 66(6), 699-723

Kamble, S., Gunasekaran, A., \& Dhone, N. C. (2020). Industry 4.0 and lean manufacturing practices for sustainable organizational performance in Indian manufacturing companies. International Journal of Production Research, 58(5), 1319-1337

Kaynak, H. (2003). The relationship between total quality management practices and their effects on firm performance. Journal of Operations Management, 21(4), 405-435

Ketchen, D. J. (2013). A primer on partial least squares structural equation modeling. Long Range Planning, 46(1-2), 184-185. https://doi.org/10.1016/j.lrp.2013.01.002

Ketokivi, M., \& Schroeder, R. (2004). Manufacturing practices, strategic fit and performance: A routinebased view. International Journal of Operations and Production Management, 24(2), 171-191

Khalfallah, M., \& Lakhal, L. (2020). The impact of lean manufacturing practices on operational and financial performance: The mediating role of agile manufacturing. International Journal of Quality and Reliability Management. https://doi.org/10.1108/IJQRM-07-2019-0244

Kock, N. (2017). Common method bias: A full collinearity assessmentmethod for PLS-SEM. In: Partial Least Squares Path Modeling: Basic Concepts, Methodological Issues and Applications (pp. 245-257). doi: https://doi.org/10.1007/978-3-319-64069-3_11 
Lagrosen, Y., \& Lagrosen, S. (2005). The effects of quality management-A survey of Swedish quality professionals. International Journal of Operations ans Production Management, 25(10), 940-952

Lameijer, B. A., Veen, D. T., Does, R. J., \& De Mast, J. (2016). Perceptions of lean six sigma: A multiple case study in the financial services industry. Quality Management Journal, 23(2), 29-44

Lewis, M. A. (2000). Lean production and sustainable competitive advantage. International Journal of Operations and Production Management, 20(8), 959-978

Lovelock, C., \& Gummesson, E. (2004). Whither services marketing? In search of a new paradigm and fresh perspectives. Journal of Service Research, 7(1), 20-41

Marodin, G., Frank, A. G., Tortorella, G. L., \& Netland, T. (2018). Lean product development and lean manufacturing: Testing moderation effects. International Journal of Production Economics, 203, $301-310$

McKinsey.(2010). India Post Mail network optimization project: speed post-KPIs and first-class mail network. Retrieved May 5, 2019, from https://www.scribd.com/presentation/120445248/McKinseyIndia-Post-Mail-Network-Optimization-Project

Möldner, A. K., Garza-Reyes, J. A., \& Kumar, V. (2020). Exploring lean manufacturing practices influence on process innovation performance. Journal of Business Research, 106, 233-249

Murugesan, V. S., Sequeira, A. H., Shetty, D. S., \& Jauhar, S. K. (2020). Enhancement of mail operational performance of India post facility layout using AHP. International Journal of System Assurance Engineering and Management, 11(2), 261-273

Narasimhan, R., \& Das, A. (2001). The impact of purchasing integration and practices on manufacturing performance. Journal of Operations Management, 19(5), 593-609

Nicholson, A., \& Pakgohar, A. (2020). Lean thinking in a UK university law clinic: A reflective case study. International Journal of Clinical Legal Education, 27(1), 171-203

Panwar, A., Jain, R., Rathore, A. P. S., Nepal, B., \& Lyons, A. C. (2018). The impact of lean practices on operational performance-An empirical investigation of Indian process industries. Production Planning and Control, 29(2), 158-169

Paul, S. K., Asian, S., Goh, M., \& Torabi, S. A. (2019). Managing sudden transportation disruptions in supply chains under delivery delay and quantity loss. Annals of Operations Research, 273(1-2), 783-814

Piercy, N., \& Rich, N. (2009). Lean transformation in the pure service environment: The case of the call service centre. International Journal of Operations and Production Management, 29(1), 54-76

Procter, S., \& Radnor, Z. (2014). Teamworking under lean in UK public services: Lean teams and team targets in her majesty s revenue and customs (HMRC). The International Journal of Human Resource Management, 25(21), 2978-2995

Ramachandran, K. (2011). Indian postal history focus on Tamilnadu. Imayaa publication.

Rauch, E., Damian, A., Holzner, P., \& Matt, D. T. (2016). Lean hospitality-Application of lean management methods in the hotel sector. Procedia CIRP, 41, 614-619

Robinson, S., Radnor, Z. J., Burgess, N., \& Worthington, C. (2012). SimLean: Utilising simulation in the implementation of lean in healthcare. European Journal of Operational Research, 219(1), 188197. https://doi.org/10.1016/j.ejor.2011.12.029

Rogerson, P. A. (2001). Statistical Methods for Geography. pp.125-153. https://doi.org/10.4135/97818 49209953

Sajan, M. P., Shalij, P. R., \& Ramesh, A. (2017). Lean manufacturing practices in Indian manufacturing SMEs and their effect on sustainability performance. Journal of Manufacturing Technology Management, 28(6), 772-793

Sakthi Nagaraj, T., \& Jeyapaul, R. (2020). An empirical investigation on association between human factors, ergonomics and lean manufacturing. Production Planning and Control, 1-15.

Shah, R., \& Ward, P. T. (2003). Lean manufacturing: Context, practice bundles, and performance. Journal of Operations Management, 21(2), 129-149

Shamsuzzaman, M., Alzeraif, M., Alsyouf, I., \& Khoo, M. B. C. (2018). Using lean six sigma to improve mobile order fulfilment process in a telecom service sector. Production Planning and Control, 29(4), 301-314

Sodhi, H. S. (2020). Lean six sigma: A clinical treatment for the recovery of Indian manufacturing sector from the after-effects of coronavirus. World Journal of Science, Technology and Sustainable Development, 17(3), 311-322

Talib, F., Asjad, M., Attri, R., Siddiquee, A. N., \& Khan, Z. A. (2020). A road map for the implementation of integrated JIT-lean practices in Indian manufacturing industries using the best-worst method approach. Journal of Industrial and Production Engineering, 37(6), 275-291

Tenenhaus, M., Vinzi, V. E., Chatelin, Y. M., \& Lauro, C. (2005). PLS path modeling. Computational Statistics and Data Analysis, 48(1), 159-205. https://doi.org/10.1016/j.csda.2004.03.005 
Thomas, A., Antony, J., Haven-Tang, C., Francis, M., \& Fisher, R. (2017). Implementing lean six sigma into curriculum design and delivery-A case study in higher education. International Journal of Productivity and Performance Management, 66(5), 577-597

Tortorella, G. L., de Castro Fettermann, D., Frank, A., \& Marodin, G. (2018). Lean manufacturing implementation: Leadership styles and contextual variables. International Journal of Operations and Production Management., 38(5), 1205-1227

Tortorella, G. L., Giglio, R., \& van Dun, D. H. (2019). Industry 4.0 adoption as a moderator of the impact of lean production practices on operational performance improvement. International Journal of Operations and Production Management, 39, 860-886

Vadivel S. M. (2015). Implementing lean ergonomics in Indian postal service industries-a case study, Unpublished MS thesis, Indian Institute of Technology Madras, (pp. 01-83).

Vlachos, I., \& Bogdanovic, A. (2013). Lean thinking in the European hotel industry. Tourism Management, $36,354-363$

Vlachos, I., \& Siachou, E. (2018). An empirical investigation of workplace factors affecting lean performance. International Journal of Productivity and Performance Management., 67(2), 278-296

Wang, F. K., \& Chen, K. S. (2010). Applying lean six sigma and TRIZ methodology in banking services. Total Quality Management, 21(3), 301-315

Womack, J., \& Jones, T. D. (1990). The machine that changed the world. Rawson Associates.

$\mathrm{Wu}, \mathrm{Z}$., Xu, J., \& Xu, Z. (2016). A multiple attribute group decision-making framework for the evaluation of lean practices at logistics distribution centers. Annals of Operations Research, 247(2), 735-757

Yadav, G., Luthra, S., Huisingh, D., Mangla, S. K., Narkhede, B. E., \& Liu, Y. (2020). Development of a lean manufacturing framework to enhance its adoption within manufacturing companies in developing economies. Journal of Cleaner Production, 245, 118726

Mahmoud, Y. M., Small, M. H., \& Marwanwafa, A. (2003). Organizational modifications to support JIT implementation in manufacturing and service operations. Omega, 31(3), 213-226

Youssef-Beshir, M., Salem-El-Sabaghl, A., \& El-Nawawi, M. A. (1981). Time on task effect on tracking performance under heat stress. Ergonomics, 24(2), 95-102

Publisher's Note Springer Nature remains neutral with regard to jurisdictional claims in published maps and institutional affiliations.

\section{Authors and Affiliations}

\section{Sengazhani Murugesan Vadivel ${ }^{1}$. Aloysius Henry Sequeira ${ }^{2}$. Robert Rajkumar Sakkariyas ${ }^{3} \cdot$ Kirubaharan Boobalan $^{4}$}

Aloysius Henry Sequeira

ahs@nitk.edu.in

Robert Rajkumar Sakkariyas

robertrajkumar2003@yahoo.com

Kirubaharan Boobalan

kiruba888@gmail.com

1 Department of Industrial and Production Engineering, The National Institute of Engineering, Mysuru 570008, India

2 School of Management, National Institute of Technology Karnataka, Surathkal 575025, India

3 Loyola - ICAM College of Engineering and Technology, Chennai, India

4 Great Lakes Institute of Management, Chennai, India 